\title{
A GRAVIDEZ INDESEJADA PROVENIENTE DO ESTUPRO PRATICADO PELA MULHER E A POSSIBILIDADE DE APLICAÇÃO DO ABORTO SENTIMENTAL
}

\author{
THE UNWANTED PREGNANCY FROM RAPE PRACTICED BY \\ WOMEN AND THE POSSIBILITY OF APPLICATION OF \\ SENTIMENTAL ABORTION
}

RVD

Recebido em

11.11 .2020

Aprovado em

05.02 .2021

\section{Eline Araújo Souza Barreira ${ }^{1}$ \\ Igor de Andrade Barbosa²}

\section{RESUMO}

Este artigo visa analisar especificamente a possibilidade de aplicação do aborto sentimental à requerimento do ofendido ou da autora do estupro, uma vez que a Lei 12.015 de 2009 passou a admitir como sujeitos ativo e passivo do crime, pessoas de ambos os sexos. A realização do trabalho, que se deu por meio da pesquisa bibliográfica em doutrinas e artigos, e da pesquisa documental na legislação, com abordagem qualitativa, aponta que a aplicação do aborto sentimental, nessas hipóteses, não encontra qualquer respaldo em nosso ordenamento jurídico, uma vez que não estão abarcadas pelo dispositivo bem como violam diversas normas e princípios constitucionais.

Palavra-chave: Aborto; Estupro; Gravidez; Lei 12.015/09.

\section{ABSTRACT}

This article aims to specifically analyze the possibility of applying sentimental abortion at the request of the victim or the perpetrator of the rape, since with Law 12.015 of 2009, people of both sexes were admitted as active and passive offenders. The

\footnotetext{
${ }^{1}$ Acadêmica do Curso de Direito do Centro Universitário Católica do Tocantins EMAIL: eline.araujo@hotmail.com. ORCID ID: https://orcid.org/0000-0003-3876-4076 CONTATO: (63) 99101-1163

2 Mestre em Direito Econômico e Desenvolvimento pelo Programa de Mestrado em Direito da Universidade Candido Mendes - UCAM. Especialista em Relações de Consumo e em Direito da Concorrência e Propriedade Industrial, ambos pela UCAM. Defensor Público Federal de $1^{\underline{a}}$ categoria na Defensoria Pública da União do Tocantins e professor de graduação e pós-graduação do curso de Direito do Centro Universitário Católica do Tocantins - UniCatólica. E-mail igor.barbosa@catolica-to.edu.br ORCID https://orcid.org/0000-0001-6337-3873
} 
accomplishment of the work, which took place through bibliographic research on doctrines and articles, and documentary research on legislation, with a qualitative approach, points out that the application of sentimental abortion in these cases does not find any support in our legal system, since it is not covered by the provision as well as violate several constitutional principles and norms.

Keywords: Abortion; Rape; Pregnancy; Lei 12.015/09.

\section{INTRODUÇÃO}

O Código Penal Brasileiro entrou em vigor em $1^{\circ}$ de janeiro de 1942, através do decreto-lei $n . .2 .848$ de 1940, e sofre desde então constantes e pontuais reformas para se adequar às novas realidades que surgem. Exemplos de tais alterações são facilmente encontrados em breve leitura do diploma legal. É fato que ao alterar um trecho da lei, possivelmente vários outros aspectos sofrerão desequilíbrio e também necessitarão de modificações. Nem sempre a emenda ocorre de forma plena e eficaz, ou seja, na maior parte das vezes, após uma alteração, restam dúvidas em torno da aplicabilidade e eficiência de determinados dispositivos.

Exemplo do supracitado ocorreu recentemente na parte especial do Código Penal, mais especificamente nos denominados "Crimes contra os costumes", que sofreu significativa mudança com a Lei ㄲo. 12.015, sancionada no dia 07 de agosto de 2009, que, dentre outras novidades, passou a admitir como sujeito ativo e passivo do crime de estupro, pessoas de ambos os sexos. Diante disso, abriu-se a possibilidade de uma gravidez decorrente da violência sexual praticada por uma mulher contra um homem.

O art. 128, II do Código Penal, por sua vez, prevê a autorização legal para realizar o aborto no caso de gravidez resultante de estupro. O que ocorre é que o dispositivo não menciona se a norma é aplicável em todos os casos, principalmente quando o homem é o ofendido.

Pretende-se dessa forma, por meio da pesquisa bibliográfica e documental, abordar especificamente as circunstâncias relevantes ligadas à gravidez da mulher 
resultante da conduta criminosa de estupro por ela mesma praticada contra um homem. Para tanto, serão apresentadas incialmente as alterações feitas pela Lei 12.105/09 no artigo 213 do Código que trata do crime de estupro e, em seguida, serão feitas algumas considerações acerca do aborto sentimental e o impacto da novatio legis na aplicação desse instituto.

Veremos que os princípios tem um grande papel nessa análise, visto que na ausência ou no choque de normas, devemos nos valer principalmente dos princípios constitucionais, pois estes guardam os valores fundamentais da ordem jurídica.

A discussão é pertinente, haja vista que a gravidez além de decorrer do ato delituoso, também repercute para além do âmbito penal, atingindo, inclusive, questões na seara cível relativas ao dever do pai em reconhecer ou não o fruto da gestação, prestar ou não os alimentos à criança nascida de uma situação de violência, dentre outros. A análise do presente tema não tem, por óbvio, a intenção de esgotar o tema, mas despertar a reflexão no sentido de alcançar novas situações até então desconhecidas para o Direito, mas perfeitamente possíveis no atual contexto social.

\section{ESTUPRO: LEI 12.015/09 E ALTERAÇÕES NO CP}

Em 2003, um estudo realizado pela Comissão Parlamentar Mista de Inquérito sobre violência e redes de exploração sexual de crianças e adolescentes apontou para a predominância, no Código Penal de 1940, de estigmas sociais e valores preconceituosos atribuídos ao objeto e as finalidades da proteção pretendida, que não mais coadunam com a atual situação de violação da liberdade sexual do indivíduo no Brasil. Em razão disso, foi proposto, em 2005, o projeto de lei 4.850 com objetivo de atualizar a legislação de acordo com as novas percepções sociais acerca da sexualidade e suas formas de exploração.

O projeto sancionado em 2009 ficou conhecido como Lei 12.015 e trouxe profundas mudanças não só no Código Penal, mas também no art. 1ํ da Lei 8.072, de 25 de julho de 1990, que dispõe sobre os crimes hediondos, para adequá-lo aos termos do inciso XLIII do art. 5ำ da Constituição Federal e na Lei 2.252, de 1ํ de julho de 1954, 
que trata de corrupção de menores, revogando-a. Compete mencionar, no entanto, as alterações realizadas no Título VI e no art. 213 do Código Penal que abordam sobre o crime de estupro.

Antes das modificações operadas no Título VI do Código Penal, o estupro e demais crimes sexuais eram abordados como "crimes contra os costumes". Masson (2020, p. 1), ao tratar do assunto, esclarece que o termo se refere à "linha de comportamento sexual imposta pelo Estado às pessoas, por necessidades ou conveniências sociais". A proteção à moral social dispensada aos crimes sexuais, apesar de ter perdido o seu sentido ao longo dos anos, prevaleceu até recentemente quando foi aprovada a Lei 12.015/09.

Em 7 de agosto de 2009 a denominação do Título VI (Dos Crimes Conta os Costumes) foi substituída para "Dos Crimes Contra a Dignidade Sexual", alterando substancialmente o bem jurídico tutelado, passando então a considerar a dignidade, sob aspecto da liberdade sexual do indivíduo, e não a moral social, como o bem mais relevante a ser protegido. Prado afirma que

(...) a liberdade sexual constitui na capacidade do sujeito de dispor livremente de seu próprio corpo à prática sexual, ou seja, a faculdade de se comportar no plano sexual segundo seus próprios desejos, tanto no tocante à relação em si, como no concernente à escolha de seu parceiro; (...) de se negar a executar ou a tolerar a realização por parte de outro de atos de natureza sexual que não deseja suportar, opondose, pois, ao constrangimento de que é objeto exercido pelo agente (PRADO, 2019, p. 551)

Gonçalves Sobrinho corrobora com o raciocínio afirmando que

Não importa seja a vítima solteira, casada ou viúva, uma vestal inatacável ou uma meretriz de baixa formação moral. Em qualquer hipótese é ela senhora de seu corpo e só entregará livremente, como, quando e a quem for de seu agrado (TJSP - AC - Rel. Des. Gonçalves Sobrinho - RJTJSP 31/362 e RT 435/106). 
Não obstante o autor tenha se referido à vítima do sexo feminino, em adequação ao novo entendimento que dispensa proteção a todos os indivíduos, sem nenhuma distinção, o mesmo deve ser aplicado também ao homem.

O consentimento é, portanto, a palavra-chave quando se discute sobre liberdade sexual e o mesmo deve ser respeitado inclusive dentro dos relacionamentos amorosos. Nesse sentido, o Código Penal contempla somente as relações sexuais não consentidas, as exploradas por terceiros e as praticadas contra vulneráveis.

Dentre outras alterações, destaca-se também a junção dos delitos de estupro e atentado ao pudor, que antes eram previstos em tipos legais autônomos (arts. $213 \mathrm{e}$ 214, respectivamente). Antes da Lei n. 12.015/09, havia inclusive controvérsias quanto à tipificação da conduta da mulher que constrangesse o homem à conjunção carnal, não caracterizaria o estupro, vez que somente a mulher era sujeito passivo. Não seria atentado violento ao pudor, pois este crime abrangia apenas os atos libidinosos diversos da conjunção carnal. Logo, a interpretação prevalecente falava em constrangimento ilegal, previsto no art. 146 do Código Penal.

Com a Lei $12.015 / 09$, os crimes de estupro e atentado violento ao pudor foram equiparados terminologicamente, passando a constituir um único crime, o de estupro, previsto no art. 213 do Código Penal. Dessa forma, o estupro, que hodiernamente considerava o homem como único sujeito ativo do crime, devido à elementar "conjunção carnal", entendida como a cópula do pênis na vagina, não distingue mais agente e nem vítima (delito comum), tendo relevância somente a identificação dos atos sexuais praticados com violência ou grave ameaça.

A Lei 12.015/09 também promoveu a substituição da expressão "mulher" por "alguém", passando a considerar que não somente a mulher, mas qualquer pessoa pode ser vítima de violência sexual. Essa mudança teve como consequência a ampliação do rol de sujeitos passivos, permitindo que este ocorra "não somente entre pessoas do sexo oposto, mas inclusive entre dois homens ou entre duas mulheres" (CAPEZ, 2019, p. 77).

De acordo com a atual previsão, o estupro consiste em constranger alguém, mediante violência ou grave ameaça, a ter conjunção carnal, isto é, introdução total ou 
parcial do pênis na vagina; a praticar ou permitir que com ele se pratiquem atos libidinosos, que são quaisquer atos sexuais que tenham por objetivo a satisfação da libido, como por exemplo, a masturbação, o sexo oral, o sexo anal, os toques íntimos, a introdução de instrumentos no ânus, na vagina ou na boca e etc.

A violência e a grave ameaça são os meios de execução do crime, podendo a primeira ser física, ou utilizando-se de meios artificiais como a água, o fogo, choque, gases etc., capazes de vencer a resistência da vítima. Bitencourt (2019, p. 55) afirma que "não é necessário que a força empregada seja irresistível, bastando que seja suficiente para coagir a vítima a permitir que o sujeito ativo realize seu intento". Já a grave ameaça exprime o "constrangimento moral imposto pelo abusador de causar dano material ou moral considerável à vítima ou contra pessoa estimada pela vítima, o que a obriga a entregar-se ao agente" (PRADO, 2020, p. 802)

O exame de corpo de delito é prescindível para a comprovação do fato e o mesmo deve ser realizado sempre que o estupro deixar vestígios. Nucci (2020, p. 958) pondera que "embora o laudo pericial seja um importante instrumento de convicção do juiz, não só desse recurso, está munido o magistrado para formar o seu convencimento", o qual também poderá colher depoimentos de testemunhas e até da própria vítima.

Quanto à sua natureza, a Lei 8.072/90 (art. 1.․, V) classifica o estupro como crime hediondo, trazendo ao condenado, por consequência, todas as privações impostas pela referida lei, dentre as quais estão: o cumprimento da pena inicialmente em regime fechado; a impossibilidade de obtenção de liberdade provisória com fiança; o aumento de prazo para a obtenção do livramento condicional e para a progressão de regime; a impossibilidade de concessão de indulto, graça ou anistia, dentre outros.

\section{ASPECTOS GERAIS DO ABORTO SENTIMENTAL}

O art. 124 do Código Penal Brasileiro preceitua que é crime a gestante abortar ou consentir que outrem the provoque aborto. Considera-se aborto a "interrupção da gravidez, com a consequente destruição do produto da concepção" (CAPEZ, 2019, p. 
188). Nas lições de Nucci (2020, p. 636), o aborto se define pela "cessação da gravidez, cujo início se dá com a nidação, antes do termo normal, causando a morte do feto ou embrião". Assim, o aborto ocorre quando se provoca dolosamente a morte do feto ainda dentro do ventre da mulher. Caso ele seja morto após ter sido expulso da barriga, fica configurado o crime de homicídio ou infanticídio, a depender das circunstâncias.

A doutrina relata seis espécies de aborto: a) o aborto natural, que é a interrupção da gravidez de maneira espontânea; b) aborto acidental, que é o ocasionado por eventos exteriores e traumáticos vivenciados pela gestante; c) o aborto criminoso, que é a interrupção forçada e voluntária da gravidez, com ou sem o consentimento da gestante, provocando a morte do feto; d) o aborto legal, que representa as hipóteses em que a lei permite a interrupção da gestação; d.1) aborto terapêutico ou necessário, que é a interrupção da gravidez realizada por recomendação médica, a fim de salvar a vida da gestante; d.2) aborto sentimental ou humanitário, que é a autorização legal para interromper a gravidez quando a mulher foi vítima de estupro; e e) aborto eugênico, que corresponde a interrupção da gravidez para evitar que a criança nasça com graves falhas genéticas.

Diante desse quadro de possibilidades de aborto, são considerados criminosos os tipos contidos nos artigos 124 a 127 do Código Penal, a saber: aborto provocado pela gestante ou com seu consentimento (art. 124, caput, CP); aborto provocado por terceiro sem o consentimento da gestante (art. 125, CP); aborto provocado por terceiro com o consentimento da gestante (art. 126, CP); e aborto qualificado (art. 127, CP).

O objeto jurídico do aborto criminoso é indiscutivelmente a vida intrauterina, isto é, o feto ou embrião, o qual é um ser independente e passível de proteção desde a sua concepção. Nesse sentido, preceitua nossa Carta Magna ao assegurar que a vida deve ser respeitada e protegida e que ninguém deve ser privada dela arbitrariamente. Por outro lado, apesar da sua enorme relevância em todos os aspectos, a vida é passível de limitação de ordem ético-jurídica a medida em que se acha em confronto com outro direito também garantido pela Constituição. A respeito dessa relativização, Marcelo Novelino afirma que: 
O direito à vida, apesar de sua importância axiológica e de ser pressuposto elementar para o exercício de todos os demais direitos, não possui um caráter absoluto. Em casos de colisão com o mesmo bem jurídico titularizado por terceiros ou, ainda, com outros princípios de peso relativo (ou seja, diante do caso concreto) maior, o direito à vida poderá sofrer restrições no seu âmbito de proteção (NOVELINO, 2014, p. 360).

Neste ponto, nota-se que assim como ocorre com todos os direitos fundamentais, não se deve atribuir um caráter absoluto ao direito à vida, sendo plenamente possível que ele venha a ceder em face de outros princípios, que diante do caso concreto, seja atribuído maior relevância. Nesse aspecto, podemos citar como exemplos onde ocorre a relativização da vida, a pena de morte em caso de guerra declarada (CF, art. 5. ${ }^{\circ}$, XLVII), as excludentes de antijuridicidade (CP, arts. 23 a 25) e as hipóteses de aborto legal (CP, 128, I e II).

O art. 128 do Código Penal aborda sob duas hipóteses de excludentes de ilicitude aplicáveis no contexto do aborto: a primeira hipótese de autorização do aborto prevista no inciso I é a do chamado aborto necessário (ou terapêutico), que consiste na intervenção cirúrgica realizada com o propósito de salvar a vida da gestante. Consoante a doutrina, trata-se de espécie de estado de necessidade.

Assim, há dois bens jurídicos (a vida do feto e da genitora) postos em perigo, de modo que a preservação de um (vida da genitora) depende da destruição do outro (vida do feto). O legislador optou pela preservação do bem maior, que, no caso, é a vida da mãe, diante do sacrifício de um bem menor, no caso, um ser que ainda não foi totalmente formado. (...) O legislador cuidou, assim, de criar um dispositivo específico para essa espécie de estado de necessidade, sem, contudo, exigir o requisito da atualidade do perigo, pois basta a constatação de que a gravidez trará risco futuro para a vida da gestante, que pode advir de causas várias, como, por exemplo, câncer uterino, tuberculose, anemia profunda, leucemia, diabetes. (CAPEZ, 2020, p. 200)

A segunda hipótese, denominada aborto sentimental, humanitário ou ético, se verifica no inciso II e se refere aos casos de gravidez resultante de estupro. Para Cobo del Rosal, tal instituto encontra o seu fundamento 
en la idea de no exigibilidad, entendida como aquel criterio orientador para decidir la prevalencia de intereses en conflicto: El Derecho no puede obligar a la mujer embarazada a soportar las consecuencias de orden personal, familiar y social que se derivarían del nacimiento de un hijo que es el fruto de un gran atentado a su dignidad y libertad (MATíAS \& MATIAS, 2020, p. 35).

O legislador fez no exercício de suas atribuições constitucionais, uma ponderação entre o direito à vida do feto e a liberdade sexual/dignidade da vítima, atribuindo maior peso aos direitos da gestante, motivado no fato de que não é razoável e nem justo que a lei obrigue a vítima a carregar em seu ventre uma criança proveniente da violência sexual sofrida. Trata-se, portanto, de uma hipótese de inexigibilidade de conduta adversa da gestante.

O dispositivo traz como elemento indispensável para a legitimação do aborto sentimental, o consentimento da gestante, ou no caso em que esta for incapaz, do seu representante legal. Prado (2019, p. 436) afirma que "mais do que um mero requisito, o consentimento constitui a autêntica base da eximente, pois é precisamente a conformidade do paciente que faz surgir o direito de agir do médico".

Jesus (2011) aponta que "o único arbitro da prática do aborto é o médico, e este deve valer-se dos meios à sua disposição para a comprovação do estupro". Caso fique comprovado que foi falsa a alegação feita pela suposta gestante, a mesma responderá pelo crime de aborto consentido (art. $124 \mathrm{CP}$ ). O médico, de outro modo, será eximido de pena em virtude da sua boa-fé e da incidência em erro de tipo, o qual afasta a tipicidade da sua conduta.

Por fim, é importante mencionar que segundo o entendimento da doutrina e da jurisprudência não é exigida sentença condenatória ou autorização judicial para proceder com o aborto, bastando que o ofendido apresente ao médico prova idônea da violência sexual.

\section{A GRAVIDEZ INDESEJADA PROVENIENTE DO ESTUPRO PRATICADO PELA MULHER E A POSSIBILIDADE DE APLICAÇÃO DO ABORTO SENTIMENTAL}


A Lei n. 12.015/2009 redefiniu o conceito de estupro, passando a considerá-lo como crime comum, o que significa que qualquer sujeito pode praticá-lo ou ser vítima dele. Surge, dessa forma, a possibilidade de uma gravidez decorrente da conjunção carnal forçada pela mulher. Nesses termos, surge o seguinte questionamento: é possível que o ofendido ou a própria autora do delito requeira a interrupção da gestação apoiados no art. 128, II, do Código Penal?

Compete esclarecer que devido à ausência de adequação do referido artigo às mudanças introduzida pela Lei 12.105/2009, recorreremos aos princípios basilares do Direito Brasileiro para fins de fundamentação e argumentação para tentar alcançar a solução jurídica mais razoável para a hipótese considerada.

O aborto sentimental ou ético, como dito anteriormente, está previsto no art. 128, II, CP e consiste na autorização legal para o médico interromper a gestação proveniente do estupro a pedido da vítima ou do seu representante legal. De acordo com Rogério Greco

O aborto sentimental se amolda a uma das causas legais da exclusão de ilicitude elencadas no art. 23 do Código Penal, a inexigibilidade de conduta adversa, que neste caso relativiza o caráter inviolável da vida garantido pela Constituição em virtude de haver conflito com outro direito fundamental, que é o da dignidade humana da gestante vítima de violência sexual. (GRECO, 2017, p. 187)

O aborto sentimental se apresenta, dessa forma, como solução para o conflito que surge entre o direito da vítima e da vida do feto, de modo que o legislador decidiu pela prevalência dos direitos da vítima, considerando que esta não deve ser obrigada a levar adiante a gravidez fruto da violência sexual sofrida. Portanto, o instituto tem como cerne a proteção da integridade psicofísica da mulher, que constitui em um dos desdobramentos da dignidade humana. De acordo com Costa

A dignidade da pessoa humana supera a condição de princípio e figura como valor do indivíduo, como núcleo exegético do ordenamento jurídico, devendo ser observado como orientador de todos os feitos relacionados à pessoa humana. Fala-se também em caráter absoluto da 
dignidade da pessoa humana, pois não haveria circunstância ou direito que pudesse tirar a sua prioridade, especialmente pelo fato de tal princípio ser um fundamento da República Federativa do Brasil, apontado no primeiro artigo da Constituição Federal. Desse modo, o fundamento aludido será sempre o guia basilar do Direito, sendo imprescindível na argumentação para relativização de certo direito em detrimento de outro, como é o caso em exame. (COSTA, 2014)

Quando a mulher é vítima de abuso sexual ela tem a sua dignidade dilacerada, os danos psicológicos causados são irreversíveis e afetam a sua vida em todos os aspectos: social, familiar, profissional e etc., e uma gravidez gerada nessa circunstância acaba agravando ainda mais a situação. "Há total supressão da vontade da mulher no coito e a mesma deverá suportar sozinha os efeitos da gestação" (COSTA, 2014), o que é inadmissível do ponto de vista ético e legal.

Tratando-se da hipótese em que a mulher comete estupro contra um homem e deste ato sobrevém à gravidez, Nucci (apud Neves) assevera que essa "não tem em momento algum a sua dignidade afrontada, não havendo, dessa forma, que se falar em sopesamento entre sua dignidade e a vida do feto". Pelo contrário, a mulher que estupra incorre com culpa ou dolo para a própria gravidez, não podendo se beneficiar da excludente presente no artigo 128, inciso II do Código Penal para eximir-se das obrigações maternas.

Também é importante mencionar que apesar da lei em sua literalidade se referir apenas à gravidez "que resulta de estupro", sem mencionar, no entanto, se a permissão é dirigida a mulher vítima ou autora, deve-se ter em conta que na época da elaboração da norma, a mulher não podia figurar no polo ativo, situação que somente se tornou possível com o advento da Lei 12.015/2009. Diante disso, não há dúvidas de que o aborto sentimental não deve ser aplicado a autora do delito, mas sim à vítima dele.

Quanto à possiblidade de interpretação extensiva ou a aplicação de analogia benéfica do aborto sentimental a favor da autora do delito, Cabette assevera que nesse caso

A "interpretação progressiva" ou "extensiva" infringiria a "mens legis", vez que jamais se pretendeu na legislação brasileira autorizar o aborto advindo de coito desejado pela mulher. A razão de ser do aborto 
sentimental é o reconhecimento pelo legislador do conflito e do sofrimento psíquico da vítima de estupro, daquela que necessitará buscar forças sobre - humanas para vencer a dor de conviver com terríveis lembranças durante a gestação e inclusive após o parto, por toda sua convivência com o filho advindo de uma relação sexual traumática. Não há de forma alguma justificativa para qualquer comiseração semelhante em relação àquela que desejou a relação sexual e até chegou ao ponto extremo de impô-la criminosamente ao homem - vítima (CABETTE, 2009).

Conforme descrito pelo autor, não há semelhanças entre a vítima e a autora do abuso sexual que justifique a aplicação de interpretação benéfica em a favor desta esta última, e do mesmo modo, não há que se conceder benefício para quem, além de ter cometido o crime e assumido o risco da gravidez, busca agora a supressão da vida de um nascituro para se livrar do ônus de ter que zelar por ele.

No que diz respeito à possibilidade de o homem vítima do estupro exigir que a mulher agressora se submeta a um procedimento abortivo, compete destacar de plano, a sua completa inviabilidade, pois se entende que além de não estar abarcada tal situação pela art. 128, Il do Código Penal, uma vez que, no caso, a mulher não é vítima e sim autora do delito e do dispositivo exigir o consentimento da gestante, não é constitucional ou tampouco razoável e justo submetê-la a um aborto, pois existe, a princípio, a prioridade do respeito à inviolabilidade da sua integridade física.

Jesus ( 2011) afirma que obrigar a infratora a abortar "consistiria em verdadeira sanção penal contra esta, solução não prevista em nosso ordenamento jurídico, ferindo frontalmente o princípio da legalidade". E mesmo que houvesse previsão nesse sentido, a mesma recairia sobre o feto, cuja vida não deve ser levada a termo em consequência de crime praticado por sua genitora. Nas palavras de Cabette (2009) tal possibilidade poderia traduzir-se em "um odioso exemplo de transcendência da lei penal, atingindo um terceiro, cuja inocência chega ao grau mais elevado imaginável".

Assim, por mais que possa parecer justo, o homem vítima de estupro pleitear o aborto sentimental, por mais que se queira equiparar sua condição à da mulher vítima, alegando que deva ser aplicado um tratamento isonômico entre eles, tal hipótese não 
encontra qualquer amparo em nosso ordenamento jurídico. De acordo com Marcelo Novelino

Os direitos de igualdade possuem uma singularidade que os diferencia dos outros direitos fundamentais. Estes possuem um âmbito de proteção no qual estão contemplados diferentes domínios (vida, liberdade, privacidade, propriedade...), cujas intervenções, para serem consideradas legítimas (restrições), devem ter uma justificação constitucional. No caso dos direitos de igualdade, não há um âmbito de proteção material e, por consequência, não há que se falar em sua restrição. O princípio da igualdade não possui um conteúdo material específico. Trata-se de um princípio que possui um caráter relacional, ou seja, pressupõe a existência de elementos de comparação para a análise da igualdade ou desigualdade do tratamento. (NOVELINO, 2014, p. 473)

No primeiro caso temos, portanto, a situação em que a mulher vítima de estupro consente para a interrupção da própria gravidez e na segunda hipótese temos o homem, também vítima de violência sexual, que solicita a interrupção da gestação da autora do estupro. É evidente que em ambas situações, apesar de terem guardadas semelhanças com relação à violação sexual, são completamente distintas, uma vez que somente a mulher pode engravidar e sofrer um aborto e o homem não. Inexiste, por exemplo, a possibilidade da mulher vítima de estupro exigir que o homem realize um aborto, pois a gravidez para este é biologicamente impossível.

Conforme Marcelo Novelino os direitos de igualdade podem ainda ser diferenciados em duas dimensões

A igualdade jurídica visa a impedir que sejam adotados tratamentos diferenciados para situações essencialmente iguais ou tratamentos iguais para situações essencialmente diferentes sem uma razão legítima para tal. A igualdade fática, por seu turno, tem por objetivo central a redução de desigualdades existentes no plano fático, o que exige necessariamente a adoção de um tratamento jurídico diferenciado. (NOVELINO, 2014, p. 474)

A Igualdade então não se limita a estabelecer obrigações idênticas aos indivíduos, não se denotando com ela uma equivalência exata de condições ou de 
cenário, mas sim um tratamento desigual que, por consequência, cause cenário com considerável proporcionalidade e razoabilidade.

Nesses termos, infere-se que não há possibilidade de conceder ao homem vítima de estupro o direito de decidir pelo aborto já que, conforme visto anteriormente, é a mulher quem estará sujeita a essa interferência, não o homem, de modo que a equiparação plena de gênero, nesse caso, depende de se respeitar a vontade da mulher. Nesse sentido preconiza Cabette

Os interesses (financeiros, patrimoniais, afetivos ou emocionais) do homem vitimizado não podem servir de pretexto para a superação da relevância maior da vida humana a ser tutelada. Seria absurdo sobrepor o interesse do vitimado em não pagar pensão ou dividir seu patrimônio em sucessão à vida humana em formação. Mesmo as questões afetivas e / ou emocionais podem ser resolvidas por outros meios que não a eliminação de uma vida. A situação do homem vitimado é bastante diversa da mulher em circunstâncias semelhantes, vez que este não precisa manter em seu corpo por nove meses torturantes o produto de uma relação sexual traumática. (CABETTE, 2009)

Jesus (2011) encerra expondo que "as consequências da paternidade indesejada e resultante de crime poderão ser minimizadas na esfera cível, no que diz respeito às obrigações daí decorrentes".

Deve-se ressaltar também que a redação do dispositivo legal deixa bem claro que condição para a realização do aborto sentimental é o consentimento da gestante ou de seu representante legal. Sem consentimento, não há intervenção médica, sob pena de o profissional ser punido, já que estamos diante de uma norma permissiva que exige elementos a serem observados para sua caracterização no plano concreto.

Por derradeiro, vale salientar que a única possibilidade legal de aborto a qual a autora do estupro pode e deve se submeter é quando este constituir o único meio de salvar a sua vida. Prado (2020, p. 435) afirma que neste caso, o consentimento da gestante é dispensável, visto que este é incompatível com o estado de necessidade. 


\subsection{A estupradora que engravida com o ato criminoso e a causa de aumento da pena}

A Lei 12.015/09 também inseriu duas novas majorantes ao art. 234-A, os quais preveem a causa de aumento da pena de metade a um terço se o crime resultar em gravidez; e se o agente transmitir à vítima doença sexualmente transmissível de que sabe ou deveria saber ser portador, ou se a vítima é idosa ou pessoa com deficiência. Com relação da causa de aumento do crime em razão do resultado gravidez, Masson faz importante consideração

A preocupação do legislador tem em mira principalmente o estupro (CP, art. 213) e o estupro de vulnerável (CP, art. 217-A), embora a gravidez também possa ser fruto de outros delitos, a exemplo da violação sexual mediante fraude (CP, art. 215). Suas consequências são nefastas para a vítima e para seus familiares, aí se incluindo até mesmo o produto da concepção. (MASSON, 2018, p. 154)

Tal dilema de optar entre levar adiante a gravidez ou realizar um aborto legal, nos termos do artigo 128, II, imposta à vítima como resultado do crime obviamente justifica a exacerbação da reprimenda face ao considerável incremento do "desvalor do resultado". No entanto, questionamentos podem advir de casos em que a autora do crime de estupro é mulher e essa vem a engravidar como resultado do coito obtido mediante violência ou grave ameaça. Nessas circunstâncias, pode-se falar em causa de aumento de pena resultante da gravidez em face da agressora? Afinal, agora a grávida é a própria autora do ilícito.

Cezar Roberto Bitencourt (2019, p. 255) considera inaplicável a majorante, pois segundo ele "não passaria de mutatis mutandis, uma espécie de autolesão, que não representa maior desvalor do resultado da conduta para a vítima." Cunha (2017) no entanto, defende a possibilidade de majoração da pena da autora do crime uma vez que lei não faz distinção à pessoa grávida. 
Nucci, no mesmo sentido que Cunha, entende que deve prevalecer a aplicação do aumento, mas afirma que a solução para o caso concreto ficará a critério do julgador, que poderá favorecer a gestante ou o feto.

Focando-se a circunstância de elevação da pena sob a ótica de maior proteção à mulher, que haveria de conviver com gestação indesejada, seria inaplicável, afinal, ela mesma engravidou, colocando-se em risco porque quis. Por vezes, ela pode pretender a gravidez, para obter um filho da vítima (questões de herança, pensão etc.). Entretanto, observando-se a mesma situação, sob o enfoque da gravidez, constitutiva de ser humano, a vir ao mundo motivado pela prática de um delito, trazendo consigo inúmeros problemas a serem deslindados entre os pais, pensamos deva ser aplicada a causa de aumento. (NUCCI, 2020, p. 794)

Data vênia às alegações feitas pelos ilustres penalistas, a orientação que parece mais acertada é a de Cabette (2009) segundo o qual entende que o "desvalor do resultado" deve ser aferido não com relação às consequências advindas da gravidez para a mulher criminosa, mas sim com relação ao homem que foi vítima. Nesse sentido, não há dúvidas que da gravidez indesejada implicará em responsabilidades financeiras (direito de alimentos, sucessão e etc.), problemas afetivo-emocionais (rejeição da criança, convivência conflituosa com a mãe criminosa, com a família, esposa/marido e filho(s) fruto de relações legais), além de que a gravidez pode, em alguns casos, constituir o próprio fim da prática delituosa.

Nesta perspectiva, depreende-se que a causa de aumento deve ser aplicada também nos casos em que a grávida é a autora do crime, pois o desvalor do resultado, conforme foi demonstrado, impulsiona para a valoração da pena.

\section{CONSIDERAÇÕES FINAIS}

A Lei 12.015/09 alterou o art. 213 do Código Penal tornando possível que um homem seja coagido por uma mulher a ter com ela conjunção carnal praticada mediante violência ou grave ameaça que resulte em gravidez. A novidade, no entanto, 
gerou dúvidas quanto ao direito do homem que foi vítima, ou até mesmo da autora do delito, de valer-se da previsão do art. 128, II CP para interromper a gestação, uma vez que a norma não é clara quanto às hipóteses da sua aplicação.

A investigação que teve como intuito esclarecer tais pontos, constatou que no primeiro caso, o homem que foi vítima de estupro não tem o direito de pleitear o aborto por diversos motivos, podendo ser citados a inviolabilidade da integridade física e psíquica da gestante, que é quem sofre no seu corpo e no seu psiquismo os efeitos da gravidez; a ofensa ao princípio da legalidade, uma vez que tal exigência poderia ser vista como uma punição não prevista no ordenamento jurídico; a ofensa ao princípio da personalidade da pena, já que o nascituro estaria respondendo por crime que não cometeu; e a igualdade da mulher, já que homens não engravidam e, portanto, a equiparação plena de gênero depende de se respeitar a vontade da mulher nessa matéria.

Com relação ao segundo caso, restou evidente que a autora do delito não pode reclamar pela interrupção da gestação que ela mesma deu causa. Ainda que o estupro não tenha sido motivado nesse sentido - como ocorre nos casos de estupro préordenado, onde a criminosa pratica o delito para constituir a gravidez e lograr de eventual pensão - ela no mínimo, correu o risco de produzir o resultado gravidez. A doutrina também entende que nesse caso a mulher não tem a sua dignidade afrontada, não havendo, dessa forma, que se falar em sopesamento entre sua dignidade e a vida do feto.

Por fim, vale destacar que nenhuma das hipóteses mencionadas se adequam à finalidade da norma, que tem como escopo a proteção da mulher vítima de estupro e não a que figura como autora do delito.

\section{REFERÊNCIAS}

BITENCOURT, Cezar Roberto. Tratado de direito penal: parte especial. Vol. 4. São Paulo: Saraiva, 2019. 
CABETTE, Eduardo Luiz Santos. A mulher como sujeito ativo do crime de estupro e as consequências do resultado da gravidez. Jus.com.br, 2009. Disponível em: <https://jus.com.br/artigos/13501/a-mulher-como-sujeito-ativo-do-crime-de-estupro-e-asconsequencias-do-resultado-da-gravidez.html> Acesso em: 03 ago. 2020.

CAPEZ, Fernando. Curso de direito penal: parte especial. Vol. 3. São Paulo: Saraiva, 2019.

. Curso de direito penal: parte especial. Vol.2. São Paulo: Saraiva, 2020.

COSTA, Anderson Pinheiro. A mulher como sujeito ativo do crime de estupro e as consequências nas esferas cível e penal. Conteúdo Jurídico, 2014. Disponível em: <http://www.conteudojuridico.com.br/consulta/Artigos/41040/a-mulher-como-sujeitoativo-do-crime-de-estupro-e-as-consequencias-nas-esferas-civel-e-penal.html> Acesso em: 26 out. 2020.

CUNHA, Rogério Sanches. Manual de direito penal: parte especial. Vol. 2. 9 ed. Salvador: Juspodvm, 2017.

GRECO, Rogério. Código Penal comentado. Niterói: Impetus, 2017.

JESUS, Damásio Evangelista de. 0 aborto sentimental e a interrupção da gravidez da autora do crime de estupro. Âmbito Jurídico, 2011. Disponível em: $<$ https://ambitojuridico.com.br/cadernos/direito-penal/o-aborto-sentimental-e-a-

interrupcao-da-gravidez-da-autora-do-crime-de-estupro.html> Acesso em: 17 set. 2020.

MASSON, Cleber. Direito penal: parte especial. Vol. 3. 10 ed. São Paulo: Forense, 2020.

MATÍAS, Julio Román Valverde; MATIAS, Tirzo Jesse Valverde. Despenalización del delito de aborto sentimental. Trujillo, 2020.

NEVES, Luciane Veiga Cozza Neves. Crimes contra a sexualidade: A mulher como sujeito ativo no delito de estupro. Âmbito Jurídico, 2019. Disponível em < https://ambitojuridico.com.br/cadernos/direito-penal/crimes-contra-a-sexualidade-amulher-como-sujeito-ativo-no-delito-de-estupro.html> Acesso em: 18 dez. 2020.

NOVELINO, Marcelo. Manual de direito constitucional. Rio de Janeiro: Método, 2014.

NUCCI, Guilherme de Souza. Código Penal Comentado. Rio de Janeiro: Forense, 2020.

NUCCI, Guilherme de Souza. Crimes contra a dignidade sexual: de acordo com a Lei 12.015/2009. São Paulo. Revista dos Tribunais, 2010. 
. Manual de direito penal. Rio de Janeiro: Forense, 2020.

PRADO, Luiz Regis. Curso de direito penal: parte geral e parte especial. 18 ed. Rio de Janeiro: Forense, 2020.

. Tratado de direito penal brasileiro: parte especial. Vol. 2. Rio de Janeiro: Forense, 2019. 